\title{
Unified Visual Working Memory without the Anterior Corpus Callosum
}

\author{
Yair Pinto ${ }^{1,2, *}$, Edward H.F. de Haan ${ }^{1,2}{ }^{-1}$, Maria-Chiara Villa ${ }^{3}{ }^{(0)}$, Sabrina Siliquini ${ }^{4}$, \\ Gabriele Polonara ${ }^{5}$, Claudia Passamonti ${ }^{6}$, Simona Lattanzi ${ }^{70}$, Nicoletta Foschi ${ }^{8}$ \\ and Mara Fabri ${ }^{7}$ \\ 1 Department of Psychology, University of Amsterdam, 1018 WS Amsterdam, The Netherlands; \\ e.h.f.dehaan@uva.nl \\ 2 Amsterdam Brain \& Cognition (ABC) Center, University of Amsterdam, \\ 1018 WS Amsterdam, The Netherlands \\ 3 Department of Psychology, University of Turin, 10124 Turin, Italy; maria_chiara.villa@edu.unito.it \\ 4 Child Neuropsychiatry Unit, Marche Polytechnic University, 60100 Ancona, Italy; \\ Sabrina.Siliquini@ospedaliriuniti.marche.it \\ 5 Department of Odontostomatologic and Specialized Clinical Sciences, Marche Polytechnic University, \\ 60020 Ancona, Italy; Gabriele.Polonara@ospedaliriuniti.marche.it \\ 6 Psychology Unit, Ospedali Riuniti, 60126 Ancona, Italy; claudia.passamonti@ospedaliriuniti.marche.it \\ 7 Department of Experimental and Clinical Medicine, Marche Polytechnic University, 60020 Ancona, Italy; \\ s.lattanzi@univpm.it (S.L.); m.fabri@staff.univpm.it (M.F.) \\ 8 Epilepsy Center-Neurological Clinic, Azienda "Ospedali Riuniti”, 60123 Ancona, Italy; \\ nicoletta.foschi@ospedaliriuniti.marche.it \\ * Correspondence: y.pinto@uva.nl
}

Received: 29 September 2020; Accepted: 11 December 2020; Published: 18 December 2020

\begin{abstract}
One of the most fundamental, and most studied, human cognitive functions is working memory. Yet, it is currently unknown how working memory is unified. In other words, why does a healthy human brain have one integrated capacity of working memory, rather than one capacity per visual hemifield, for instance. Thus, healthy subjects can memorize roughly as many items, regardless of whether all items are presented in one hemifield, rather than throughout two visual hemifields. In this current research, we investigated two patients in whom either most, or the entire, corpus callosum has been cut to alleviate otherwise untreatable epilepsy. Crucially, in both patients the anterior parts connecting the frontal and most of the parietal cortices, are entirely removed. This is essential, since it is often posited that working memory resides in these areas of the cortex. We found that despite the lack of direct connections between the frontal cortices in these patients, working memory capacity is similar regardless of whether stimuli are all presented in one visual hemifield or across two visual hemifields. This indicates that in the absence of the anterior parts of the corpus callosum working memory remains unified. Moreover, it is important to note that memory performance was not similar across visual fields. In fact, capacity was higher when items appeared in the left visual hemifield than when they appeared in the right visual hemifield. Visual information in the left hemifield is processed by the right hemisphere and vice versa. Therefore, this indicates that visual working memory is not symmetric, with the right hemisphere having a superior visual working memory. Nonetheless, a (subcortical) bottleneck apparently causes visual working memory to be integrated, such that capacity does not increase when items are presented in two, rather than one, visual hemifield.
\end{abstract}

Keywords: split-brain; working memory; attention; visual memory; corpus callosum 


\section{Introduction}

Working memory is a key cognitive process in humans. It is needed to achieve goals, such as navigating through traffic, understanding situations, and producing coherent language. Due to its prominence, working memory has been extensively investigated. However, several fundamental issues remain unsolved. Firstly, when it comes to visual working memory the location of the neural basis is unclear. Some studies suggest that it resides mainly in the frontal cortical areas [1,2], whereas other research suggests that occipital areas are the primary source [3,4]. Secondly, it is unclear what unifies visual working memory. In other words, why is capacity roughly the same regardless of whether all items are presented in one visual hemifield, or across the entire visual field? This question is based on the observation that visual information in the left hemifield is projected to the right hemisphere and vice versa [5-8]. Thus, if each hemisphere would have its own, independent, memory storage, then items that are presented across the visual field capacity should be the sum of the capacity when items are presented in the left and the right hemifield-we will elaborate on this in more detail later on.

A prime candidate underlying the unification of visual working memory seems to be the corpus callosum. In humans, nearly all communication between the cerebral hemispheres flows through the corpus callosum [9-11]. Thus, if full-field working memory is housed in both hemispheres, then it seems almost inevitable that the unification of memory processing relies on the corpus callosum.

Interestingly, both issues are related. This can be understood by assuming that working memory is located in the frontal cortical areas. The brain contains two frontal cortices-one in the left hemisphere and one in the right hemisphere. Let us consider what happens if the connections between the left and right frontal cortex are severed. If the frontal cortex is indeed the seat of working memory, then this would cause two independent working memory storages. As mentioned, it is important to note that visual information from the left hemifield is initially processed by the right hemisphere and vice versa [5-8]. Thus, if there are two independent working memory storages, it could be that the working memory storage in the left hemisphere exclusively (or primarily) stores visual information coming from the right hemifield and the storage in the right hemisphere records information from the left hemifield. In some sense, this is what disunified working memory implies, not one integrated storage for the entire visual field, but different independent storages for different parts of the visual field. In other words, if working memory is housed in the frontal cortex, and the corpus callosum unifies working memory, then it can be expected that severing the frontal parts of the corpus callosum disunifies working memory.

If two independent memories exist, this can be clearly established. Let us assume that each independent working memory has a capacity of $\mathrm{N}$, i.e., each storage can contain $\mathrm{N}$ items. That means that the storage in the left hemisphere can record $\mathrm{N}$ items from the right visual field and similarly for the other hemisphere. Thus, if the subject is presented with $2 \mathrm{~N}$ items, with $\mathrm{N}$ items in each hemifield, then all items can be stored. Yet, if the same $2 \mathrm{~N}$ items are presented within one hemifield only $\mathrm{N}$ of them can be recorded. In short, if working memory storage is disunified and each hemisphere has its own storage that only stores items of one visual field, then memory capacity will be double when items are presented bilaterally (i.e., in two visual fields) rather than unilaterally (i.e., in one visual field). Note that under normal circumstances working memory is unified. That is, although working memory may be somewhat elevated when items are presented bilaterally rather than unilaterally capacity does not double in the bilateral condition [12,13].

Interestingly, visual attention, which is arguably closely related to working memory [14,15], can sometimes be disunified in healthy subjects. For instance, during multiple object tracking (MOT, [16-19]) the subject attentively follows multiple moving items at once. Interestingly, the number of items that a subject can track during MOT doubles when the items are presented bilaterally, rather than unilaterally, even when controlling for average distance between the items [20,21]. This suggests that MOT is disunified, and each cerebral hemisphere tracks moving objects in one visual field independently from the other hemisphere. Indeed, electroencephalogram (EEG) research has revealed 
that when a tracked item crosses from one visual field to another, a transfer of information seems to occur, where one hemisphere informs the other [22].

In the current research, we investigated two split-brain patients in whom the anterior parts of the corpus callosum have been removed. This removal prevents direct communication between the frontal parts of the cerebral cortex. We studied if the visual working memory in these patients remains unified, or is split. If it is split, this would suggest that working memory is seated in the frontal cortex and is unified through the anterior parts of the corpus callosum. However, if working memory remains unified, then one of these two assertions is likely invalid.

\section{Method}

\subsection{Participants}

We tested two split-brain patients in this investigation. In Experiments $1-3$ we tested patient MC. MC was 21 years old at the time of this study. He received his first callosotomy, in which 2/3 of the anterior part of the corpus callosum was cut, when he was 16 years old. The remainder of the anterior part of the corpus callosum was cut when MC was 17 years old. In total, 4/5 of the entire corpus callosum of MC (the entire anterior part of the corpus callosum) was severed (leaving only the splenium and the posterior part of the isthmus intact). The IQ of MC was 85 both before and after the operation.

In Experiments 4 and 5 we tested DDC. DDC had undergone full corpus callosum resection in order to relieve drug-resistant epilepsy. Moreover, his anterior commissure was almost entirely removed as well. See Fabri et al., 2006 [23], Pizzini et al., 2010 [24], and Corballis et al., 2010 [25], for a detailed description of this patient.

See Figure 1 for recent Magnetic Resonance Imaging (MRI) scans of MC and DDC. The studies were approved by the ethical committee of the Marche Polytechnic University, Ancona, Italy, Protocol n. 210/655. Both subjects were extensively informed before each experiment and explicitly consented before participating.
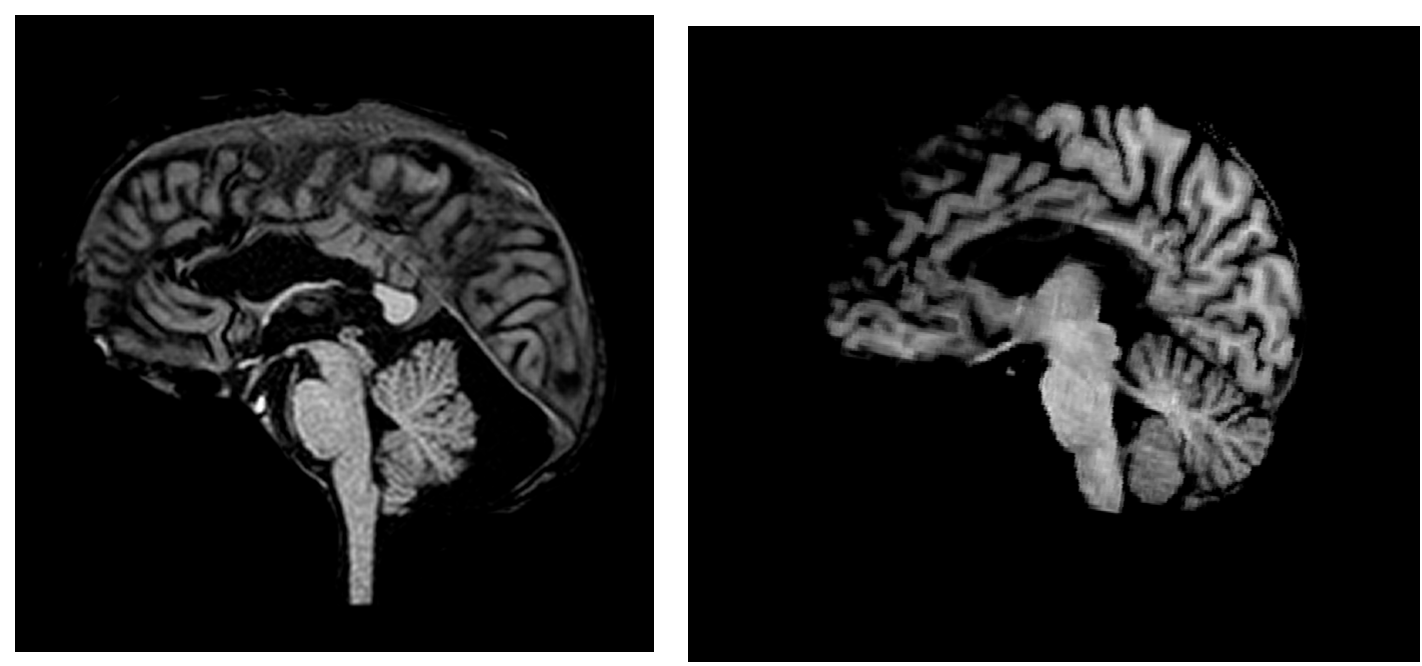

Figure 1. Magnetic Resonance Imaging (MRI) scans of patient MC (left) and DDC (right).

\subsection{Stimuli and Procedure}

In all experiments, the participant was seated $50 \mathrm{~cm}$ away from the screen (width of the screen: $46^{\circ}$ of visual angle; height: $26^{\circ}$ ). The fixation spot was black (luminance: $0 \mathrm{~cd} / \mathrm{m}^{2}$ ) and had a diameter of $0.86^{\circ}$. The background was light gray (Commission Internationale de $1^{\prime}$ Eclairage (CIE) x, y: 0.279, 0.304; luminance: $5.56 \mathrm{~cd} / \mathrm{m}^{2}$ ). 
See Figure 2 for an overview of the procedure. Each trial started with a red fixation spot (radius $0.36^{\circ}$, CIE: $\mathrm{x}, \mathrm{y}: 0.641,0.341$ luminance: $11.9 \mathrm{~cd} / \mathrm{m}^{2}$ ) in the centre of the screen on an otherwise blank, white, background (CIE: $x, y: 0.289,0.317$ luminance: $63.2 \mathrm{~cd} / \mathrm{m}^{2}$ ), presented for $0.5 \mathrm{~s}$. Then the memory display, consisting of a fixation spot and 6 cartoon pictures (size: $2.37^{\circ} \times 3.35^{\circ}$ ) and the same white background, appeared for $0.12 \mathrm{~s}$. The cartoon pictures were presented on an imaginary circle around fixation (radius of the circle: $6.57^{\circ}$ ). There were four conditions, left visual field, right visual field, upper field, and lower field. In the first condition, all items appeared in the left visual field, the items were distributed evenly across the imagery circle, with the first item at $15^{\circ}$ and the final item at $165^{\circ}$ where $0^{\circ}$ is a straight line, up from fixation, $90^{\circ}$ is a straight line to the right from fixation, etc. In the second condition, the items appeared on the imaginary circle from $105^{\circ}$ to $255^{\circ}$. In the third condition the items appeared on the imaginary circle from $285^{\circ}$ to $75^{\circ}$. Finally, in the fourth condition the items appeared on the imaginary circle from $195^{\circ}$ to $345^{\circ}$. Thus, in all conditions the inter-item distance was identical, but in the first two conditions all items appeared in one visual field, whereas in the final two conditions the items appeared distributed across both visual fields. In one third of the trials, all of the items appeared in the left visual field, in another third, all of the items appeared in the right visual field, in one sixth the items appeared in the upper field and in anther sixth of the trials the items appeared in the lower field. All conditions were randomly intermixed throughout the session.
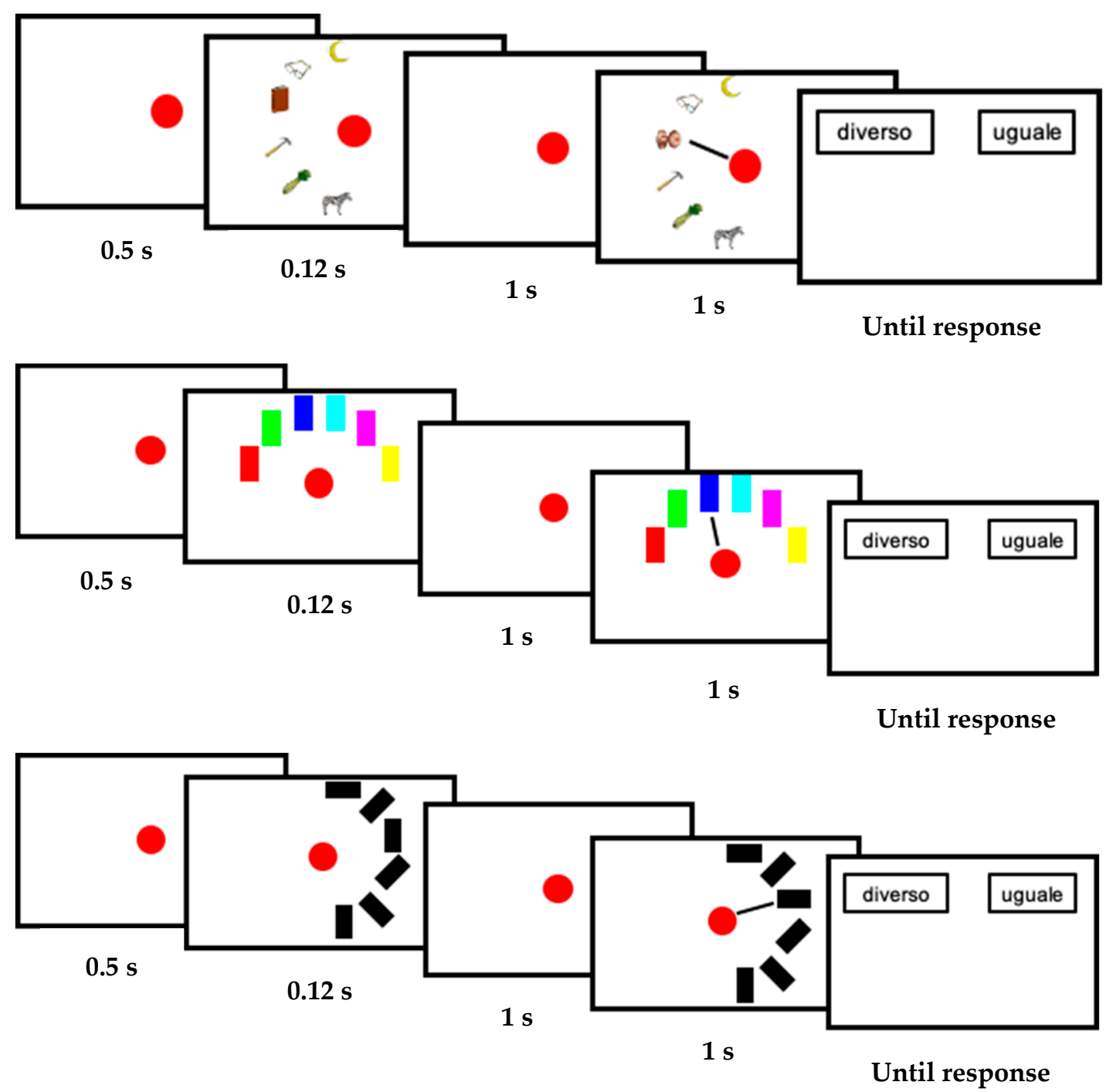

Figure 2. Cont. 

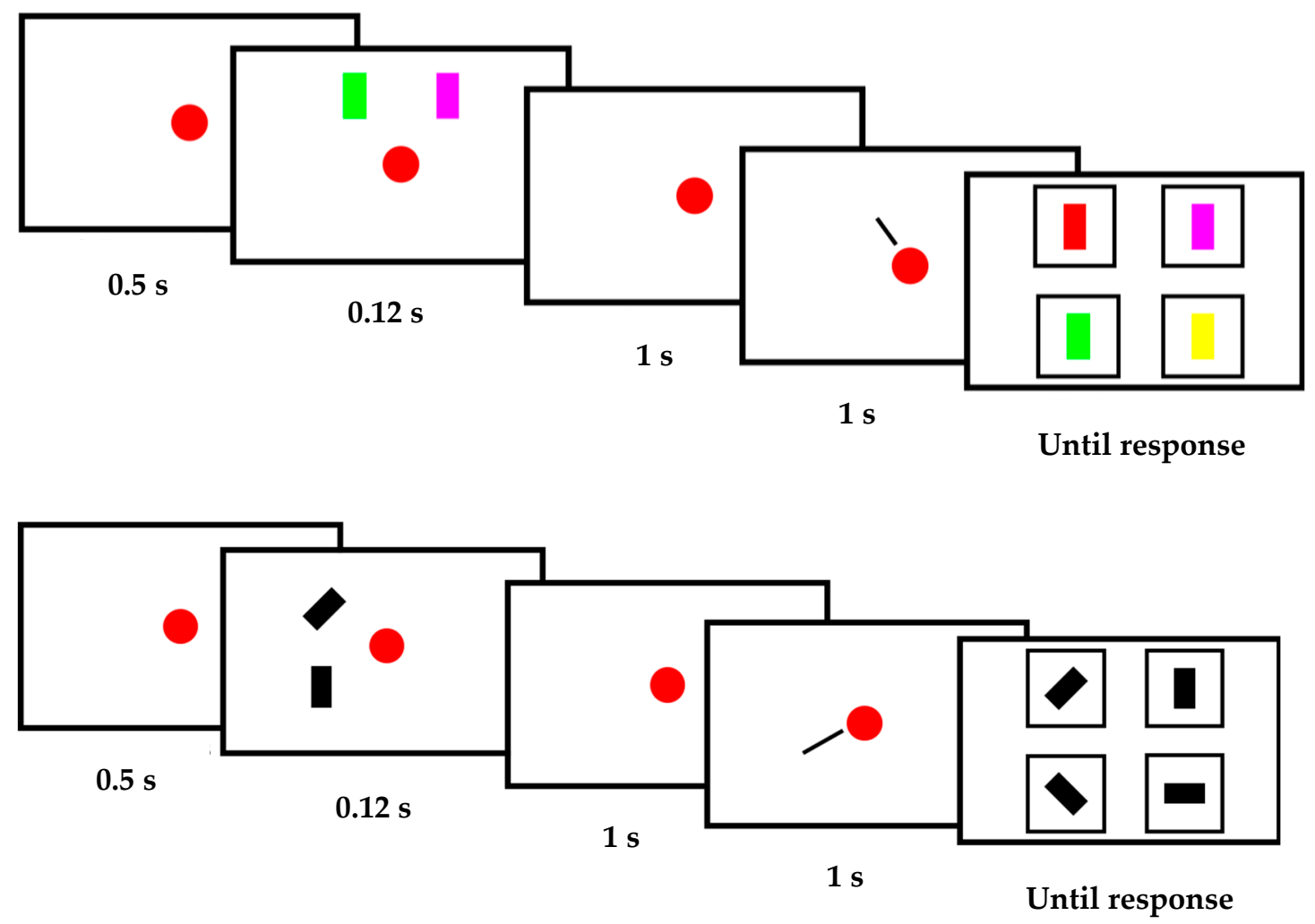

Figure 2. From top to bottom, an overview of Experiments 1-5. In all of the experiments, visual working memory was tested. MC performed Experiments 1-3 and DDC performed Experiments 4 and 5. "Diverso" indicates different, meaning that the item at the cued location changed from memory to test display. "Uguale" indicates same, meaning that the item at the cued location was the same in both the memory and test display.

Subsequently the fixation spot was presented again, on an otherwise blank white background, for $1 \mathrm{~s}$. Then, the test display appeared for $1 \mathrm{~s}$. The test display was identical to the memory display (with the addition of a 2-pixel wide cue, length of the cue: $3.95^{\circ}, \mathrm{CIE}: \mathrm{x}, \mathrm{y}: 0.279,0.304$ luminance: $5.56 \mathrm{~cd} / \mathrm{m}^{2}$ ) on $50 \%$ of the trials. Each location was equally likely to be cued. On the other $50 \%$ of the trials, the test display was identical to the memory display (with the addition of a cue), except that the cartoon picture at the cued location in the test display was different from the cartoon picture at the cued location in the memory display. After offset of the test display, the participant indicated whether the item at the location indicated by the cue changed from the memory display to the test display.

Experiment 2 was the same as Experiment 1, except instead of cartoon pictures, we employed colored rectangles (height: $2.85^{\circ}$, width: $1.13^{\circ}$ ). Possible colors: cyan, CIE: $x, y: 0.214,0.312$ luminance: $51.2 \mathrm{~cd} / \mathrm{m}^{2}$; green, CIE: $\mathrm{x}, \mathrm{y}: 0.293,0.606$ luminance: $44.7 \mathrm{~cd} / \mathrm{m}^{2}$; yellow, CIE: $\mathrm{x}, \mathrm{y}: 0.405,0.521$ luminance: $56.7 \mathrm{~cd} / \mathrm{m}^{2}$; light green, CIE: $\mathrm{x}, \mathrm{y}: 0.314,0.59$ luminance: $46.4 \mathrm{~cd} / \mathrm{m}^{2}$; blue, CIE: $\mathrm{x}, \mathrm{y}: 0.148$, 0.072 luminance: $6.47 \mathrm{~cd} / \mathrm{m}^{2}$; red, CIE: $\mathrm{x}, \mathrm{y}: 0.641,0.341$ luminance: $11.9 \mathrm{~cd} / \mathrm{m}^{2}$; purple, CIE: $\mathrm{x}$, y: $0.286,0.147$ luminance: $18.4 \mathrm{~cd} / \mathrm{m}^{2}$; red-blue, CIE: $\mathrm{x}, \mathrm{y}: 0.502,0.265$ luminance: $12.9 \mathrm{~cd} / \mathrm{m}^{2}$. For each trial, 6 colors were randomly selected. The background color of the screen was dark gray (CIE: $x, y$ : $0.279,0.304$ luminance: $5.56 \mathrm{~cd} / \mathrm{m}^{2}$ ) and the fixation spot and the cue were white (CIE: $\mathrm{x}, \mathrm{y}: 0.289$, 0.317 luminance: $63.2 \mathrm{~cd} / \mathrm{m}^{2}$ ).

Experiment 3 was the same as Experiment 2, except now the memoranda consisted of white oriented rectangles (CIE: $x, y: 0.289,0.317$ luminance: $63.2 \mathrm{~cd} / \mathrm{m}^{2}$ ). Possible orientations of the rectangle: $0^{\circ}, 45^{\circ}, 90^{\circ}$, and $135^{\circ}$ (where $0^{\circ}$ indicates vertical, $90^{\circ}$ horizontal, and $45^{\circ}$ and $135^{\circ}$ right oblique and left oblique, respectively). If a rectangle changed from memory to test display, its orientation changed by $90^{\circ}$. 
See Figure 2 for an overview of the procedure of Experiments 4 and 5. Experiment 4 was the same as Experiment 2 except for the following changes. The memory display, consisted of a fixation spot and 2 colored rectangles. In the left visual field condition, the items appeared at $225^{\circ}$ and $315^{\circ}$. In the right visual field condition, the items appeared at $45^{\circ}$ and $135^{\circ}$. In the upper field condition, the items appeared at $315^{\circ}$ and $45^{\circ}$. In the lower field condition, the items appeared at $225^{\circ}$ and $315^{\circ}$. Moreover, the test display consisted only of the fixation spot and a cue highlighting one location. Finally, the response display appeared and remained visible until the participant responded. The response display consisted of four differently colored rectangles, among them both colored rectangles that were present in the memory display. Experiment 5 was the same as Experiment 4, except now instead of 2 colored rectangles, 2 oriented rectangles (similar to Experiment 3 ) were presented.

In all of the experiments, each session consisted of 3 blocks of 24 trials. MC performed 288 trials, across 4 sessions of Experiment, 1504 trials across 7 sessions of Experiment 2, and 576 trials across 8 sessions of Experiment 3. DDC performed 288 trials across 4 sessions of Experiment 4 and 144 trials across 2 sessions of Experiment 5 . The number of trials per experiment was determined by logistical constraints. That is, we had a limited amount of testing time per subject, and distributed this time over several experiments. The experiments were self-paced, such that the subject took as many breaks as deemed necessary, leading to a variable amount of trials per allotted time slot.

\subsection{Analysis}

We calculated capacity in Experiments $1-3$ as follows: Capacity $=$ set size * $2 *$ (accuracy-0.5). In Experiments 4 and 5, capacity was calculated as follows: Capacity $=$ set size $* 4 / 3 *$ (accuracy-0.25). The logic behind these formulas is that if the subject does not know the answer, he will have to guess randomly and, thus, have an accuracy of 50\% in Experiments 1-3 and 25\% in Experiments 4 and 5. If he does know the answer, his accuracy is $100 \%$. Moreover, the subject will know the answer on capacity/set size fraction of the trials. Bilateral capacity was defined as the average of the capacity in the upper and lower field conditions. Unilateral average was defined as the average of the capacity in the left and right visual field conditions, whereas unilateral sum was defined as the sum of the capacity in the left and right visual field conditions.

\section{Results}

See Figure 3 for an overview of the results. We tested statistical differences between capacity in the different conditions through permutation testing, where we compared accuracy in the bilateral condition to capacity of the unilateral sum of capacity or the unilateral average of capacity. The main result is that in all of the experiments the bilateral capacity was significantly lower than the sum of the capacities in the unilateral conditions, and in 4 of the 5 experiments this difference was significant (Exp.1: $p=0.006$, Exp.2: $p<0.001$, Exp.3: $p<0.001$, Exp.4: $p=0.033$, and Exp.5: $p=0.089$ ). Yet, in none of the experiments bilateral capacity was significantly larger than the unilateral average (Exp.1, $p=0.87$; Exp.2, $p=1$; Exp.3, $p=0.131$; Exp.4, $p=0.817$; Exp.5, $p=0.583$ ). However, on average, across Experiments 1-3, the bilateral capacity was slightly higher than the average unilateral capacity (i.e., $12.9 \%$ higher), whereas across Experiments 4 and 5, the bilateral capacity was $22.7 \%$ higher than average unilateral capacity. Note that these results are similar to what is found in healthy adults, in whom bilateral working memory capacity is slightly higher in the bilateral than the unilateral conditions but far from being the sum of the capacities per hemifield $[12,13]$. 

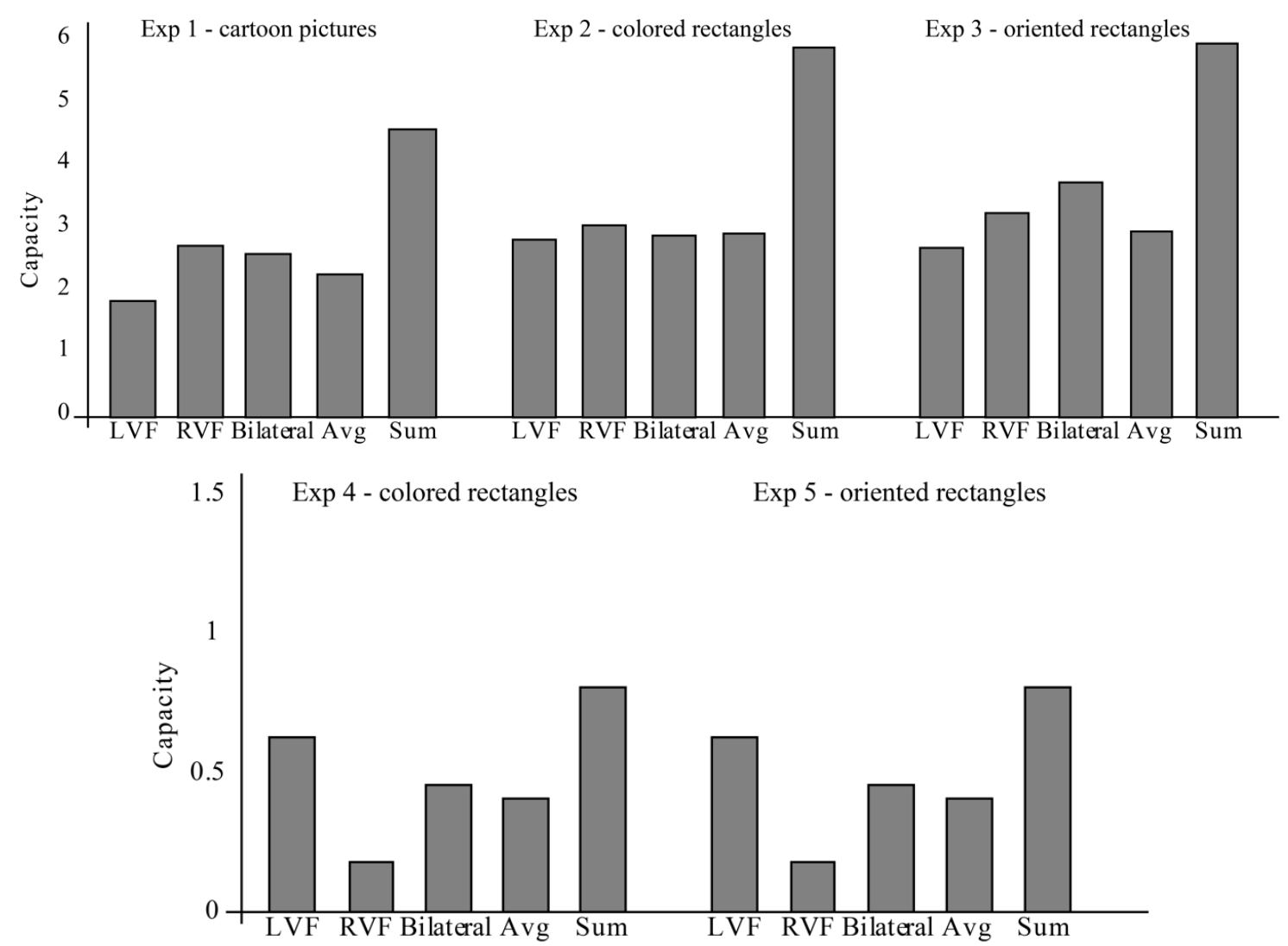

Figure 3. An overview of the results of Experiments 1-5. The top panel shows the results of Experiments 1-3, the bottom panel shows the results of Experiments 4 and 5. LVF indicates left visual field, RVF right visual field, Bilateral is the average of upper and lower field. Avg indicates the average of the unilateral conditions, Sum indicates the sum of the unilateral conditions. Capacity is depicted on the $y$-axis. The results clearly show that across experiments capacity in the bilateral condition is only slightly higher than the average capacity in the unilateral conditions.

\section{Discussion}

To summarize our results, in two patients without the anterior part of the corpus callosum visual working memory capacity was similar in the bilateral and the unilateral condition. This suggests that visual working memory remains largely unified in the absence of most of the corpus callosum.

\subsection{Visual Working Memory versus General Working Memory}

One important point of note here is that we investigated visual working memory, however, this may not generalize to working memory in general. Specifically, visual short-term memory consists of different stages that have different features and different neural underpinnings. Iconic memory $[26,27]$ is considered to be the most low-level representation of visual stimuli. This storage seems to be retinotopic and represents unbound visual features [26]. Its neural basis seems to be the early visual cortex [28]. Fragile visual short-term memory is an object-based visual memory [29], which is less low-level than iconic memory, but is still visual and not cognitive in nature. Furthermore, this visual store seems to be located in the occipital cortex, specifically $\mathrm{V} 4[3,29]$. The final visual short-term memory storage is visual working memory, which may be less visual specific, and more abstract in nature $[26,29,30]$. This visual storage may be more based in anterior cortical structures [31]. This subdivision of visual short-term memory is not uncontroversial [32,33]. Yet, the main point here is that visual short-term memory may not be a perfect proxy for working memory in other settings. Working memory is often thought of as a short-term memory storage in which abstract information is held and manipulated. Yet, the early stages of visual short-term memory storage is mainly passive and sensory specific. Moreover, 
working memory is thought to be closely related to attention $[14,15]$, whereas the early stages of visual short-term memory seem to be attention independent $[34,35]$. However, note that the early stages of visual short-term memory are only assessed when the memory probe appears shortly after the visual display has disappeared and no visual masks appear in between the visual display and the memory probe $[26,29]$. Yet, in the current task we employed a change detection task in which a visual mask (either as test display or response display) did appear. Thus, we can be fairly confident that in the current set-up visual working memory, and not one of the earlier visual short-term memory storages, was assessed.

Thus, one limitation of our research is that it is not completely certain that we have only probed visual working memory, but other types of visual memory as well. There are two other noteworthy limitations. First, as nearly all (visual) working memory studies show, when it comes to capacity there are strong individual variations. This indicates that working memory is not uniform across individuals. Here, we generalized, based on two individuals, to the population at large. Our research concerns the neural basis of the unity of working memory, and not working memory capacity. It seems less likely that individual variations play a large role here. Yet, we do not yet know for sure that the neural processes underlying the unity of working memory are similar across individuals. Second, our study only addresses visual working memory. Since cognition and visual perception are substantially different in many respects, it is not certain that our findings regarding visual working memory generalize to other types of (cognitive) working memory.

\subsection{Asymmetry of Visual Working Memory}

In our current data, we found that DDC performed better when items appeared in the left visual field. Since information in the left visual field is projected to the right hemisphere, this indicates that storage of visual information is superior in that hemisphere. This finding is in line with what we found in our previous studies [36,37]. Note that it is also congruent with several studies that also suggest that in healthy adults the right hemisphere is more important for visual working memory than the left hemisphere [38,39].

Although both hemispheres seem to contribute differently to visual working memory, some unification does seem to occur. After all, if each hemisphere would store information completely independently of the other, then capacity in the bilateral condition should be the sum of the capacity in the unilateral conditions. However, this is not the case, neither with healthy adults, or patients without most, or all, of the corpus callosum.

\subsection{Subcortical Unification}

If we did indeed assess visual working memory, then our results seem somewhat surprising. After all, as mentioned, there are several indications that visual working memory is located in the frontal cortical areas. Moreover, these areas are directly connected across hemispheres through the anterior parts of the corpus callosum. Thus, it seems that cutting these connections should disunify visual working memory. However, this does not automatically follow. After all, it is possible that other, indirect, routes underly the unity of visual working memory. Note that the spontaneous regeneration of these direct connections is unlikely. In MC, the operation was performed recently. In DDC, the operation was performed more than two decades ago. However, fairly recent brain imaging revealed that no parts of the corpus callosum had spontaneously regenerated [24,25].

One possibility is that unification does not occur directly through connections between the frontal structures, but indirectly via the occipital cortex. That is, visual information is initially processed in the occipital cortex. During this processing the information is shared across hemispheres through the posterior part of the corpus callosum. Subsequently, this information is processed and stored in the frontal cortical areas. If this is how visual working memory is unified, then the anterior corpus callosum plays no role in its unification. Note that such an explanation may be able to explain why visual working memory is unified in MC, yet it cannot explain why visual working memory is unified 
in DDC. However, this is not a decisive argument against this explanation since DDC's capacity was so low that his data are inconclusive.

The second possibility is that visual working memory is unified through subcortical structures. This may seem unlikely, but other attention related processes are subcortically unified as well, so it may not be impossible. A prominent example of subcortical unification of an attentional process is the attentional blink. The attentional blink denotes the phenomenon that when two targets in a rapid visual stream follow each other with a delay between these targets of 200-500 milliseconds, the second target is often missed $[40,41]$. That is, attentional engagement with the first target seems to cause an 'attentional blink' for the second target. In healthy adults, the attentional blink occurs across visual fields. If there are two rapid visual streams, one in each hemifield, then the second target is often missed, even if the targets appear in separate streams. Interestingly, this cross-hemisphere blink also occurs in split-brain patients $[42,43]$. Thus, even in the absence of the corpus callosum the attentional blink remains unified across visual fields. Note that such subcortical unification of an attention related process is possible, but it does not always occur. For instance, when healthy adults perform a visual search task, their search efficiency is similar regardless of whether items are displayed bilaterally or unilaterally. However, split-brain patients perform a visual search twice as efficiently when items are presented bilaterally $[44,45]$, suggesting that visual search becomes disunified, i.e., each hemisphere searches through one visual field independently of the other-without the corpus callosum. For a more extensive overview of which attentional processes are unified or split in the absence of the corpus callosum, see our recent overview work $[37,46]$. In short, given that some attentional processes are unified through subcortical structures, it is possible that the same holds for visual working memory.

\section{Conclusions}

In the current research we have shown that visual working memory remains unified in the absence of the anterior parts of the corpus callosum. This implies that visual working memory is not located in the frontal cortex and/or visual working memory is not unified through direct callosal connections between the frontal cortices. Moreover, DDC's performance indicates that visual working memory is not a symmetric capability, since the right hemisphere seems to have somewhat superior capacity.

Author Contributions: Conceptualization, Y.P. and E.H.F.d.H.; methodology, Y.P. and M.-C.V.; software, Y.P. and M.-C.V.; validation, Y.P., E.H.F.d.H. and M.-C.V.; formal analysis, Y.P. and E.H.F.d.H.; investigation, Y.P., E.H.F.d.H., M.-C.V., S.S., G.P., C.P., S.L., N.F. \& M.F.; resources, Y.P., E.H.F.d.H., M.-C.V., S.S., G.P., C.P., S.L., N.F. \& M.F.; data curation, Y.P. and E.H.F.d.H.; writing-original draft preparation, Y.P., E.H.F.d.H., M.-C.V. and M.F.; writing-review and editing, Y.P., E.H.F.d.H., M.-C.V. and M.F.; visualization, Y.P., E.H.F.d.H., M.-C.V. and M.F.; supervision, Y.P., E.H.F.d.H. and M.F.; project administration, Y.P., E.H.F.d.H., M.-C.V. and M.F.; funding acquisition, Y.P. and E.H.F.d.H.. All authors have read and agreed to the published version of the manuscript.

Funding: This work was supported by a European Research Council Advanced grant FAB4V (\#339374) to Edward de Haan, and a Templeton grant (ID \#61382, "Towards understanding a unified mind") to Yair Pinto. Furthermore, we would like to thank Gabriella Venanzi and Pamela Rosettani for their cooperation in this research.

Conflicts of Interest: The authors declare no conflict of interest. The funders had no role in the design of the study; in the collection, analyses, or interpretation of data; in the writing of the manuscript, or in the decision to publish the results.

\section{References}

1. Ester, E.F.; Sprague, T.C.; Serences, J.T. Parietal and frontal cortex encode stimulus-specific mnemonic representations during visual working memory. Neuron 2015, 87, 893-905. [CrossRef]

2. Miller, E.K.; Erickson, C.A.; Desimone, R. Neural mechanisms of visual working memory in prefrontal cortex of the macaque. J. Neurosci. Off. J. Soc. Neurosci. 1996, 16, 5154-5167. [CrossRef]

3. Sligte, I.G.; Scholte, H.S.; Lamme, V.A. V4 activity predicts the strength of visual short-term memory representations. J. Neurosci. Off. J. Soc. Neurosci. 2009, 29, 7432-7438. [CrossRef]

4. Van Kerkoerle, T.; Self, M.W.; Roelfsema, P.R. Layer-specificity in the effects of attention and working memory on activity in primary visual cortex. Nat. Commun. 2017, 8, 1-14. [CrossRef] 
5. Arcaro, M.J.; McMains, S.A.; Singer, B.D.; Kastner, S. Retinotopic organization of human ventral visual cortex. J. Neurosci. Off. J. Soc. Neurosci. 2009, 29, 10638-10652. [CrossRef]

6. Cowey, A. Cortical maps and visual perception the grindley memorial lecture. Q. J. Exp. Psychol. 1979, 31, 1-17. [CrossRef]

7. Penfield, W.; Boldrey, E. Somatic motor and sensory representation in the cerebral cortex of man as studied by electrical stimulation. Brain J. Neurol. 1937, 60, 389-443. [CrossRef]

8. Wandell, B.A.; Brewer, A.A.; Dougherty, R.F. Visual field map clusters in human cortex. Philos. Trans. R. Soc. B Biol. Sci. 2005, 360, 693-707. [CrossRef]

9. Gazzaniga, M.S. Cerebral specialization and interhemispheric communication: Does the corpus callosum enable the human condition? Brain 2000, 123, 1293-1326. [CrossRef]

10. Innocenti, G.M. General organization of callosal connections in the cerebral cortex. In Sensory-Motor Areas and Aspects of Cortical Connectivity; Springer: Boston, MA, USA, 1986; pp. 291-353.

11. Wahl, M.; Lauterbach-Soon, B.; Hattingen, E.; Jung, P.; Singer, O.; Volz, S.; Klein, J.C.; Steinmetz, H.; Ziemann, U. Human motor corpus callosum: Topography, somatotopy, and link between microstructure and function. J. Neurosci. Off. J. Soc. Neurosci. 2007, 27, 12132-12138. [CrossRef]

12. Holt, J.L.; Delvenne, J. A bilateral advantage in controlling access to visual short-term memory. Exp. Psychol. 2014, 61, 127. [CrossRef] [PubMed]

13. Umemoto, A.; Drew, T.; Ester, E.F.; Awh, E. A bilateral advantage for storage in visual working memory. Cognition 2010, 117, 69-79. [CrossRef] [PubMed]

14. Chun, M.M. Visual working memory as visual attention sustained internally over time. Neuropsychologia 2011, 49, 1407-1409. [CrossRef] [PubMed]

15. Olivers, C.N.; Meijer, F.; Theeuwes, J. Feature-based memory-driven attentional capture: Visual working memory content affects visual attention. J. Exp. Psychol. Hum. Percept. Perform. 2006, 32, 1243. [CrossRef]

16. Howe, P.D.; Cohen, M.A.; Pinto, Y.; Horowitz, T.S. Distinguishing between parallel and serial accounts of multiple object tracking. J. Vis. 2010, 10, 11. [CrossRef]

17. Pinto, Y.; Howe, P.D.; Cohen, M.A.; Horowitz, T.S. The more often you see an object, the easier it becomes to track it. J. Vis. 2010, 10, 4. [CrossRef]

18. Pinto, Y.; Scholte, H.S.; Lamme, V.A.F. Tracking moving identities: After attending the right location, the identity does not come for free. PLoS ONE 2012, 7, e42929. [CrossRef]

19. Pylyshyn, Z.W.; Storm, R.W. Tracking multiple independent targets: Evidence for a parallel tracking mechanism. Spat. Vis. 1988, 3, 179-197. [CrossRef]

20. Alvarez, G.A.; Cavanagh, P. Independent resources for attentional tracking in the left and right visual hemifields. Psychol. Sci. 2005, 16, 637-643. [CrossRef]

21. Cavanagh, P.; Alvarez, G.A. Tracking multiple targets with multifocal attention. Trends Cogn. Sci. 2005, 9, 349-354. [CrossRef]

22. Drew, T.; Mance, I.; Horowitz, T.S.; Wolfe, J.M.; Vogel, E.K. A soft handoff of attention between cerebral hemispheres. Curr. Biol. 2014, 24, 1133-1137. [CrossRef] [PubMed]

23. Fabri, M.; Polonara, G.; Mascioli, G.; Paggi, A.; Salvolini, U.; Manzoni, T. Contribution of the corpus callosum to bilateral representation of the trunk midline in the human brain: An fMRI study of callosotomized patients. Eur. J. Neurosci. 2006, 23, 3139-3148. [CrossRef] [PubMed]

24. Pizzini, F.B.; Polonara, G.; Mascioli, G.; Beltramello, A.; Foroni, R.; Paggi, A.; Salvolini, U.; Tassinari, G.; Fabri, M. Diffusion tensor tracking of callosal fibers several years after callosotomy. Brain Res. 2010, 1312, 10-17. [CrossRef]

25. Corballis, M.C.; Birse, K.; Paggi, A.; Manzoni, T.; Pierpaoli, C.; Fabri, M. Mirror-image discrimination and reversal in the disconnected hemispheres. Neuropsychologia 2010, 48, 1664-1669. [CrossRef] [PubMed]

26. Sligte, I.G.; Scholte, H.S.; Lamme, V.A.F. Are there multiple visual short-term memory stores? PLoS ONE 2008, 3, e1699. [CrossRef] [PubMed]

27. Sperling, G. The information available in brief visual presentations. Psychol. Monogr. Gen. Appl. 1960, 74, 1-29. [CrossRef]

28. Thomas, L.E.; Irwin, D.E. Voluntary eyeblinks disrupt iconic memory. Percept. Psychophys. 2006, 68, 475-488. [CrossRef]

29. Pinto, Y.; Sligte, I.G.; Shapiro, K.L.; Lamme, V.A.F. Fragile visual short-term memory is an object-based and location-specific store. Psychon. Bull. Rev. 2013, 20, 732-739. [CrossRef] 
30. Sligte, I.G.; Vandenbroucke, A.R.; Scholte, H.S.; Lamme, V. Detailed sensory memory, sloppy working memory. Front. Psychol. 2010, 1, 175. [CrossRef]

31. Sligte, I.G.; Wokke, M.E.; Tesselaar, J.P.; Scholte, H.S.; Lamme, V.A. Magnetic stimulation of the dorsolateral prefrontal cortex dissociates fragile visual short-term memory from visual working memory. Neuropsychologia 2011, 49, 1578-1588. [CrossRef]

32. Makovski, T. Are multiple visual short-term memory storages necessary to explain the retro-cue effect? Psychon. Bull. Rev. 2012, 19, 470-476. [CrossRef] [PubMed]

33. Oberauer, K.; Farrell, S.; Jarrold, C.; Lewandowsky, S. What limits working memory capacity? Psychol. Bull. 2016, 142, 758. [CrossRef] [PubMed]

34. Pinto, Y.; Vandenbroucke, A.R.; Otten, M.; Sligte, I.G.; Seth, A.K.; Lamme, V.A.F. Conscious visual memory with minimal attention. J. Exp. Psychol. Gen. 2017, 146, 214-226. [CrossRef] [PubMed]

35. Vandenbroucke, A.R.; Sligte, I.G.; Lamme, V.A. Manipulations of attention dissociate fragile visual short-term memory from visual working memory. Neuropsychologia 2011, 49, 1559-1568. [CrossRef]

36. Pinto, Y.; Neville, D.A.; Otten, M.; Corballis, P.M.; Lamme, V.A.F.; de Haan, E.H.F.; Foschi, N.; Fabri, M. Split brain: Divided perception but undivided consciousness. Brain 2017, 140, 1231-1237. [CrossRef]

37. Pinto, Y.; de Haan, E.H.F.; Lamme, V.A.F. The split-brain phenomenon revisited: A single conscious agent with split perception. Trends Cogn. Sci. 2017, 21, 835-851. [CrossRef]

38. Dundas, E.M.; Plaut, D.C.; Behrmann, M. The joint development of hemispheric lateralization for words and faces. J. Exp. Psychol. Gen. 2013, 142, 348-358. [CrossRef]

39. Hong, K.; Lee, S.K.; Kim, J.; Kim, K.; Nam, H. Visual working memory revealed by repetitive transcranial magnetic stimulation. J. Neurol. Sci. 2000, 181, 50-55. [CrossRef]

40. Raymond, J.E.; Shapiro, K.L.; Arnell, K.M. Temporary suppression of visual processing in an RSVP task: An attentional blink? J. Exp. Psychol. Hum. Percept. Perform. 1992, 18, 849-860. [CrossRef]

41. Shapiro, K.L.; Raymond, J.; Arnell, K. The attentional blink. Trends Cogn. Sci. 1997, 1, 291-296. [CrossRef]

42. Giesbrecht, B.; Kingstone, A. Right hemisphere involvement in the attentional blink: Evidence from a split-brain patient. Brain Cogn. 2004, 55, 303-306. [CrossRef] [PubMed]

43. Ptito, A.; Brisson, B.; Dell'Acqua, R.; Lassonde, M.; Jolicœur, P. The attentional blink within and across the hemispheres: Evidence from a patient with a complete section of the corpus callosum. Biol. Psychol. 2009, 82, 64-69. [CrossRef]

44. Luck, S.J.; Hillyard, S.A.; Mangun, G.R.; Gazzaniga, M.S. Independent attentional scanning in the separated hemispheres of split-brain patients. J. Cogn. Neurosci. 1994, 6, 84-91. [CrossRef] [PubMed]

45. Luck, S.J.; Hillyard, S.A.; Mangun, G.R.; Gazzaniga, M.S. Independent hemispheric attentional systems mediate visual-search in split-brain patients. Nature 1989, 342, 543-545. [CrossRef] [PubMed]

46. de Haan, E.H.F.; Corballis, P.M.; Hillyard, S.A.; Marzi, C.A.; Seth, A.; Lamme, V.A.F.; Volz, L.; Fabri, M.; Schechter, E.; Bayne, T.; et al. Split-brain: What we know now and why this is important for understanding consciousness. Neuropsychol. Rev. 2020, 30, 224-233. [CrossRef]

Publisher's Note: MDPI stays neutral with regard to jurisdictional claims in published maps and institutional affiliations.

(C) 2020 by the authors. Licensee MDPI, Basel, Switzerland. This article is an open access article distributed under the terms and conditions of the Creative Commons Attribution (CC BY) license (http://creativecommons.org/licenses/by/4.0/). 